[CONTRIBUTION FROM THE JOHA: HARRISON LABORATORY OF CHEMISTRY, jo. 76.]

\title{
THE BEHAVIOR OF CERIUM, LANTHANUM, NEODYMIUM, PRASEODYMIUM, THORIUM AND ZIRCONIUM TOWARD ORGANIC BASES. ${ }^{1}$
}

\author{
BY BURT LAWS HARTWEIL \\ Recerved ALjust Is, 1903.
}

AN INVESTIGATION along these lines seemed to promise well because of the success which Jefferson ${ }^{2}$ met while prosecuting a similar study with a linited number of aromatic bases. It was hoped that some organic base would be found, among the large number to be tried, which would lead to the separation of thor ium and zirconium, or, failing in this, that a method would be disclosed by which these two elements could be separated from cerium, lanthanum, reodymium and praseodymium.

Large quantities of thorium and zirconium nitrates were prepared from the mineral thorite and zircon. Numerous qualitative tests were made and the solvents for the bases were, in most cases, water and alcohol, or mixtures of these two, depending upon the solubility of the base. In some instances ether was added to advantage. Alcohol, above a certain strength, precipitated the thorium and zirconium nitrate solutions, so that this point had to be constantly considered during the testing. The salt solution was ustally added in small quantities at a time to the solution containing a liberal amount of the organic base. Heat was applied, if precipitation did not occur in the cold. The solutions were not permitted to stand for long periods, as it was thought that differences which did not manifest themselves readily, under ordinary conditions, would scarcely indicate the probability of practical quantitative separations.

The bases studied in this investigation were obtained from Kahlbaum. Those employed by Jefferson ${ }^{3}$ were usually omitted here.

REAGENTS WHICH PRODLCLD NO RRECIPITATE WITII SALTS OF ANE ONE OF THE SIX ELEMENTS.

Benzylaniline.

Dimethylnitrosamine.

$p$-Nitraniline.

$p$-Nitrophenylhydrazine.

1 From author's thesis for the Ph.D. degree.

2 This Journal, 24, 540 .

roc. cit. 
Dipropylnitrosamine.

$m$-Nitraniline.

$0-$ Nitraniline.

0 -Chloraniline.
Piperine.

Succinimide.

Tetranitromethylaniline.

REAGEXTS WHICH CAUSED PRECIPITATES WITI SALTS OF ALI SIX OF THE ELEMENTS.

Allylamine.

Benzylmethylamine.

Bornylamine.

Camphylamine.

Diamylamine.

Diberzylamine.

Diethylamine.

Dimethylamine.

Dipropylamine.

Ethylenediamine.

Heptylamine.

Hexylamine.

Isobutylamine.

Isotributylamine.
Isodibutylamine.

Monoamylamine.

Monethylamine.

Monomethylamine.

Monopropylamine.

Neuritie.

Normal butylamine.

Normaldibutylamine.

Propylenedianine.

Tetrethylammonium hydroxide.

Tetramethylammonium bydroxide.

Triethylamine.

Trimethylamine.

Tripropylamine.

REAGENTS WHICH PRECIPITATED ONLY THORIUM AND ZIRCONIUM.

Benzidine.

$m$-Bromaniline.

$p$-Bromaniline.

p-Bromphenylhydrazine.

$p$-Chloraniline.
Isoquinoline.

$\alpha$-Picoline.

$p$-Toluidine.

$m$-Toluylenediamine.

Tribenzylamine.

REAGENTS NOT INCLUDED IN THE PRECEDING GROUPS AND WHOSE REACTIONS ARE MENTIONED UPON SUCCEEDING PAGES.

$m$-Chloraniline.

Diethylaniline.

Hexamethylenetetramine.

Monethylaniline.

Monomethylaniline.

$\alpha \cdot$ Naphthylamine.
3-Naphthylamine.

Tetrahydroquinoline. $m$-Toluidine. 0 -Xylidine.

$p$-Xylidine.

The bases of the first and second groups were manifestly unsuited for the purpose in mind. Those of the third and fourth groups showing differences in deportment with the several elements under consideration were given more particular attention, while those which were insoluble in dilute alcoholic solutions were placed to one side. The following paragraphs record the observations made with the several bodies which seemed best adapted for quantitative separations.

l Loc. eit. 
Thoriun and Zirconium aith the Chloranilines. - The different behaviors of the chloranilines substantiate the riews held regarding their relative basicity. ${ }^{1} \quad o$-Chloraniline did not precipitate thorium or zirconium. $m$-Chloraniline precipitated zirconium in the cold. but with thorium, heat was required to produce precipitation, while $p$-chloraniline precipitated the solutions of both elements even in the cold. Solutions of cerium, lanthanum, neodymimm and praseodymium salts were not affected by these reagents.

Zirconimn and Thorim aith m-Chloraniline-M Much work was done upon $m$-chloraniline to arrive at the proper conditions in the strength of alcohol and temperature favorable to the complete precipitation of the zirconium solutions, and at the same time to leave the thorium salt unprecipitated. A solution containing equal parts of water and commercial alcohol was found most satisfactory. At a temperature of $60^{\circ}-70^{\circ}$, this solvent containing $m$-chloranilire occasioned no precipitation in solutions of thorium nitrate, while in zirconium nitrate solutions it precipitated 0.0995 gram, 0.0988 gram, 0.0990 gram and 0.0988 gram of zirconium oxide, instead of 0.0995 gram obtained by ammonia or 0.0993 gram by direct evaporation and ignition. On repeating the experiment with a mixture of the thorium and zirconium nitrates, both elements were completely precipitated.

Thorinn and Zirconium with Hoxamethylenetetranine (Formin).-Formin in the qualitative tests showed a marked difference in behavior. Thus a thorium solution, after its addition, stood forty-two hours at room temperature without the appearance of a precipitate. Lpon adding the zirconium nitrate solution, both hydroxides were precipitated completely.

$\alpha$ - and $\beta$-Naphthylamine, $m$-bromaniline and $p$-bromphenylhydrazine precipitated zirconium solutions much more completely than those of thorium, but separations could not be effecter by means of them. They reacted indifferently with the salts of cerium, lanthanum, neodymium and praseolymium. o-Bromaniline was not tried at all in this investigation.

In a solution of the nitrates of zirconium and cerium, $m$-chloraniline precipitated 0.0532 gram of zirconium oxide, instead of $0.0539 \mathrm{gram}$ obtained with ammonia water. $p$-Chloraniline precipitated $0.0536 \mathrm{gram}, m$-bromaniline $0.0524 \mathrm{gram}$, and $\beta$-naph-

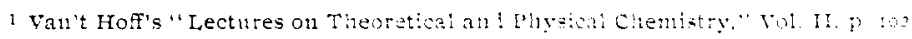


thylamine 0.0533 gram. In the first three filtrates 0.0396 gram, 0.0400 gram and 0.0395 gram, respectively, of cerium oxide were obtained, instead of the theoretical 0.0389 gram. In using $p$-chloraniline with a solution containing twice the quantities of zirconium and cerium oxide given above, a very satisfactory quantitative separation resulted.

In precipitating a mixture of zirconium and cerium salts with p-toluidine, 0.134I gram of zirconium oxide was found, while the theoretical amount present was 0.1347 gram. This same reagent added to a solution of thorium and cerium nitrates precipitated 0.1246 gram, 0.1235 gram and 0.1261 gram, instead of 0.1247 gram.

While monomethylaniline precipitated cerium solutions conpletely and apparently had no marked effect upon those of lanthanum, neodymium and praseodymium, the attempts at quantitative separations were fruitless. Diethylaniline precipitated cerium salts quite completely. The insolubility, however, of this reagent compelled the use of such large amounts of alcohol that serious difficulties arose. These were not overcome. A quantitative separation of cerium from lanthanum was made by means of tetrahydroquinoline. Two precipitations of the cerium were necessary.

$o-$ and $p$-Xylidine, as well as monethylaniline, precipitated cerium completely from its salt solutions. $m$-Toluidine seemed inadequate for this purpose.

$p$-Toluidine.-From observations made in the qualitative way, it appeared not improbable that $p$-toluidine might be employed to separate zirconium and thorium from lanthanum, neodymium and praseodymium. Accordingly, determinations were made in abont Ioo cc. of the weak alcoholic solutions, a moderate heat being applied to hasten the reaction. The precipitates formed were quite voluminous and somewhat gelatinous, especially in the case of zirconium, and well adapted for bringing down the accompanying element. On this account one reprecipitation was carried out in each case. The first precipitates dissolved readily in dilute nitric acid, especially if the solutions in the case of zirconium were not allowed to become too warm. The accompanying element was precipitated by ammonia from the combined filtrates. The ignition of the precipitates was conducted with free access of air, in 
a porcelain crucible usually, and the blast-lamp used till constant weights were obtained. All of the weights, recorded in grams, are given in the condensed form below". The weights given as "required" were obtained by direct precipitation of the elements, separately, and blasting to constant weight, and represent the average of two closely agreeing results. The "combined" oxides represent the sum of the individual oxides. The results obtained in many cases do not agree well with the standard, but it was thought best to include all which, so far as known, were carried through without accident. Some minor differences in manipulation, such as varying the strength of alcohol, time of digestion, temperature, and volume of solution, were made in different cases. These variations may have influenced the results in some instances.

ZIRCONIUNI AND LANTHANUM.

\begin{tabular}{|c|c|c|c|c|c|}
\hline \multicolumn{2}{|c|}{ Zirconium oxide. } & \multicolumn{2}{|c|}{ Latithanum oxicie. } & \multicolumn{2}{|c|}{ Combined oxides. } \\
\hline Found & Required. & Found. & Required. & Fonnd. & Required. \\
\hline 0.1342 & 0.1341 & 0.0399 & 0.0409 & O. I $74 \mathrm{I}$ & $0.175^{\circ}$ \\
\hline 0.1301 & O.I34 & 0.0993 & 0.1023 & 0.2294 & 0.2364 \\
\hline 0.1314 & $0.134 \mathrm{I}$ & 0.1025 & 0.1023 & o 2339 & 0.2364 \\
\hline 0.1367 & 0.1341 & 0.0954 & 0.1023 & $0.232 \mathrm{I}$ & 0.2364 \\
\hline
\end{tabular}

ZIRCONIUM AND NEODYMIUM.

$\begin{array}{cccccc}\text { Zirconium oside. } & \text { Feodynium oxicie. } & \text { Combined oxides. } \\ \text { Found. } & \text { Required. } & \text { Found. } & \text { Requited. } & \text { Fond. } & \text { Required. } \\ 0.1349 & 0.1341 & 0.0413 & 0.0457 & 0.1762 & 0.1798 \\ 0.1439 & 0.1341 & 0.0973 & 0.1142 & 0.2412 & 0.2487 \\ 0.1372 & 0.1341 & 0.1102 & 0.1142 & 0.2474 & 0.2487 \\ 0.1446 & 0.134 I & 0.0952 & 0.1142 & 0.2398 & 0.2487\end{array}$

ZIRCONIUM AND PRASEODYMIUM.

\begin{tabular}{|c|c|c|c|c|c|}
\hline \multicolumn{2}{|c|}{ Zirconium oxide. } & \multicolumn{2}{|c|}{ Praseodyminm oxide. } & \multicolumn{2}{|c|}{ Combined oxides. } \\
\hline Found. & Required. & Found. & Reguired. & Found. & Required. \\
\hline 0.1317 & $0.134 \mathrm{I}$ & 0.0420 & 0.0458 & 0.1737 & 0.1799 \\
\hline 0.1 .344 & $0.134 \mathrm{I}$ & D. I099 & 0.1144 & 0.2443 & 0.2485 \\
\hline 0.1312 & $0.134 I$ & 0.1129 & O.II 4 it & 0.244 & 0.2485 \\
\hline O. I 304 & $0.134 I$ & O.IOI 4 & O.I. 44 & 0.2318 & 0.2485 \\
\hline
\end{tabular}

THORITH AND LANTHANUM.

\begin{tabular}{|c|c|c|c|c|c|}
\hline \multicolumn{2}{|c|}{ Thotium oxide. } & \multicolumn{2}{|c|}{ Lanthanum oxide. } & \multicolumn{2}{|c|}{ Combined oxides. } \\
\hline $\begin{array}{l}\text { Found. } \\
0.1254\end{array}$ & $\begin{array}{c}\text { Required. } \\
0.1247\end{array}$ & $\begin{array}{l}\text { Found. } \\
0.0407\end{array}$ & $\begin{array}{l}\text { Required. } \\
0.0409\end{array}$ & $\begin{array}{l}\text { Found. } \\
0.166 \text { I }\end{array}$ & $\begin{array}{c}\text { Required. } \\
\text { o. } 1656\end{array}$ \\
\hline O. 1222 & 0.1247 & not det. & 0.1023 & $\ldots$ & $\ldots \ldots$ \\
\hline 0.1246 & O.I 247 & 0.1035 & 0.1023 & $0.228 \mathrm{I}$ & $0.227^{\circ}$ \\
\hline 0.1243 & 0.1247 & 0.1034 & 0.1023 & 0.2277 & 0.2270 \\
\hline
\end{tabular}


BEHAVIOR OF CERIUM, ETC., TOWARD ORGANIC BASES. II 33

THORIUM AND NEODYMIUM.

\begin{tabular}{|c|c|c|c|c|c|}
\hline \multicolumn{2}{|c|}{ Thorium oxide. } & \multicolumn{2}{|c|}{ Neodymium oxide. } & \multicolumn{2}{|c|}{ Combined oxides. } \\
\hline Found. & Required. & Found. & Required. & Found. & Required. \\
\hline 0.1254 & O. I 247 & 0.0464 & 0.0457 & 0.1718 & 0.1704 \\
\hline 0.1232 & O. I 247 & 0.1146 & 0.1142 & $0.237^{8}$ & $0.23^{89}$ \\
\hline 0.1242 & 0.1247 & O. IJ 42 & 0.1142 & 0.2384 & 0.2389 \\
\hline 0.1242 & 0.1247 & 0.1129 & 0.1142 & $0.237^{1}$ & $0.23^{89}$ \\
\hline 0.1248 & 0.1247 & 0.1118 & 0.1142 & 0.2366 & 0.2389 \\
\hline
\end{tabular}

THORIUM AND PRASEODYMIUM.

Thorium oxide.

Found. Required.

O.I $253 \quad 0.1247$

$0.1214 \quad 0.1247$

$0.123^{8}$

0.1246

o. 1247

o. 1247

Praseodymium oxide.

Found. Required.

$0.0471 \quad 0.045^{8}$

$0.1 I 47 \quad 0.1 I 44$

o. I I60

$0 . I I 44$

not det.

O. II 44

Combined oxide.

Found. Requited.

0.17140 .1705

$0.236 I \quad 0.239 I$

$0.2398 \quad 0.239 I$

It will be noticed that the results with zirconium are not so satisfactory as those with thorium. This cannot be attributed to any difference in manipulation for they were obtained under similar conditions, the usual practice being to carry on the six separations at one time.

A tendency on the part of zirconium to resist separation from other elements is again indicated here. This tendency is exhibited by its precipitation being retarded by the presence of another element, and by the fact that when once brought down it frequently is contaminated by that element. In the attempts to separate zirconium from thorium by $m$-chloraniline, it was repeatedly noticed that conditions of digestion, sufficient to cause precipitation of zirconium by itself, were inadequate when thorium was present, and when the precipitate was thrown down it was badly contaminated with thorium. Similar observations were made when formin was used to effect their separation; in that case all of the thorium came down with the zirconium under conditions which failed to precipitate thorium when alone. It might be supposed that this peculiar behavior of zirconium would not be noticed upon passing from thorium to the more basic elements, but a number of the results obtained in connection with lanthanum and praseodymium show incomplete precipitations of zirconium, while neodymium was so inclined to come down with zirconium that a satisfactory separation could only be expected when all possible precautions had been taken to prevent it. 
The oxides obtained by ammonia from the filtrates weighed less in the separations from zirconium than in those from thorium. If one attempts to attribute this difference to the greater solvent action of the filtrates from the zirconium, the only respect that suggests itself in which the two sets of filtrates differed is that they probably contained different amounts of the precipitant, p-toluidine. More of this reagent was necessary to effect a precipitation in the solutions containing thorium than in those in which zirconium was present, and it is probable that in carrying out the two precipitations, as was done in each instance, considerably more $p$-toluidine accumulated in the filtrates from the thorium. Sufficient attention was not given to this point while the determinations were being made to warrant an opinion as to the extent of its influence and it is merely offered as a possible explanation. As both the first and second precipitations were usually made from about $100 \mathrm{cc}$. of solution, the combined filtrates and washings, in which the precipitations by ammonia were made, were of considerable volume, and the question of the solvent effect of all this solution upon the precipitate produced by ammonia presented itself at the time of the determinations. The final filtrates were usually partially distilled, the bulk of the alcohol and ammonia being obtained in the distillate, from which the alcohol was recovered. More ammonia was repeatedly added to the undistilled portions to see if iurther precipitation would take place. In a few instances the entire solution was evaporated to dryness and the residue ignited and weighed. The weights obtained substantiall: made goot the discrepancies between the combined oxides "obtained" and "required," but as no blank determinations were made it was not proved that some of this may not have come from extraneous sources.

As previously stated, the recorded results were obtained by the use of the blast-lamp till practically constant weights resulted. The writer is of the opinion, hovever, that errors may have occurred in this comnection due to a constant composition not always being obtained, especially with lanthantm, neodymium and praseodymium. The weights obtained, by blasting the first two, were frequently to per cent. lower than those obtained by igniting over a Burisen burner; there was less difference with praseodymium. Hitcheock ${ }^{1}$ found that neodymium and praseodymium sesquioxides, by gentle ignition with free air access, 
gradually took on cxygen till the weights approximated those represented by the formula $\mathrm{M}_{2} \mathrm{O}_{7}$.

Herzfeld ${ }^{1}$ speaks of neodymium oxide as having a blue color and assigns to it the composition $\mathrm{Nd}_{2} \mathrm{O}_{3}$, and again, ${ }^{2}$ in an abstract from Shapleigh's investigation, mentions a suboxide as a gray powder and a peroxide as a dirty gray powder. The oxide obtained in the present investigation was invariably of a light brown color resembling cocoa powder, after ignition with the Bunsen burner, and was usually changed to a light blue or light purple color by blasting. It was often necessary to pulverize and blast a long time before the bluish color was uniformly obtained; indeed, in some instances part of the oxide still retained the cocoa color even though by excessive blasting practically no change in weight resulted. In view of the inadequate and somewhat conflicting information concerning neodymium oxides, the composition of the oxide obtained in any particular case must receive careful attention. The change of color produced by blasting the lanthanum and praseodymium oxides was not sufficient to indicate a change in composition, but the weights, especially with lanthanum, were considerably reduced and the certainty of a definite composition should also be established in this instance.

The most that was attempted, during the present work, with any of the oxides, was to compare the weights obtained in the course of the analyses with those obtained by direct precipitation from the aqueous solutions by ammonia, and blasting until they were constant within a few tenths of a milligram. It would seem as though the oxides obtained in this manner would be of constant composition, but it is not improbable that small variations may have occurred and that lack of nice conformity may occasionally be attributed in part to this cause. The mechanical condition of the oxides previous to blasting was not always the same, and it seems not improbable that this fact may be of some importance where intense blasting is resorted to in order to remove the last traces of oxygen necessary to effect a complete transition from an oxide which, for example, is stable at the temperature reached by the Bunsen burner to one of a lower state of oxidation which may be the stable form at the temperature produced by the more intense heat of the blast-lamp. Judging from the experience of Hitch- 
cock, and from the fact that blasting invariably reduced the weights, it seems probable that, in the case of some of the elements, at least, an oxide of a higher state of oxidation was more stable over the Bunsen burner than over the blast-lamp. Such behaviors have been noticed with some of the more common elements.

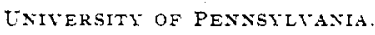

\section{FLUORIDE OF GOLD. ${ }^{1}$}

\section{BY VICTOR IENHER.}

Received September 8 , zو०3.

IXASMLCH as flucrspar is frequently associated with gold in nature, and quite notably so in the deposits of the telluride ores, it has seemed important to study gold fluoride in order to determine, if possible, whether this substance can play any part in the genesis of these deposits.

The known compounds of gold with the halogens chlorine, bromine and iodine, are, as a rule, fairly well defined. In the trivalent condition, gold forms the relatively stable chloride while the bromide and iodicle show greater tendency to break down into the lower state of valence of gold.

The halides in which gold shows a monovalence have received considerable attention, and it is known with a reasonable degree of certainty under what conditions aurous chloride, bromide, and iodide are capable of existence.

While the chlorides, bromides and iodides of gold have received more or less study, comparatively little is known of fluoricle of gold. Prat" has prepared an intermediate oxide of gold, $\mathrm{Aul}_{2} \mathrm{O}_{2}$, by the incomplete solution of gold in aqua regia, in which the hydrochloric acid is in excess, treating the solution with sufficient potassium bicarbonate to dissolve the precipitate formed, and warning the clear orange-yellow solution to $95^{\circ}$, when a clark olive-green precipitate was obtained which, when dried, showed the composition $\mathrm{Au}_{1 .} \mathrm{O}_{2}$. In studying the properties of this oxide, Prat states that hydrofuoric acicl combines with it but without dissolving it. In his study of the action of fluorine on the various metals, Moissan states that at a red heat, gold is attacked by

1 Read before the wisconsin Acndemy of science, December 26, 1902, and published in the Transactions.

2 Compt. rend., $70,8+3$. 